\title{
Management of adnexal torsion by laparoscopic approach
}

\author{
Ibrahim Alkatout • Liselotte Mettler • Martin Anlauf • \\ Walter Jonat • Christel Eckmann-Scholz • \\ Thoralf Schollmeyer
}

Received: 3 February 2012 / Accepted: 8 March 2012 /Published online: 22 March 2012

(C) Springer-Verlag 2012

\begin{abstract}
The study aimed to evaluate the effectiveness and safety of laparoscopic management of adnexal torsion. Early minimal invasive surgical management of adnexal torsion with the main emphasis on an organ-preserving procedure can safely be recommended. Although the incidence of adnexal torsions has increased, the morbidity rate has declined due to safer diagnostics and operative strategies. This is a retrospective case-control study (Canadian Task Force classification II-3) of 33 cases of adnexal torsion over an 11year period (December 1999-September 2010) in a gynecologic endoscopy unit of a university hospital. Interventions include early diagnostic laparoscopy and utmost protection of the surrounding tissue. Thirty-three cases of laparoscopically managed adnexal torsions were analyzed. Fifty-two percent had conservative organ-sparing procedures, while $48 \%$ underwent resection of ovary, tube, or both. The mean operating time was $69.2 \mathrm{~min}$. There were no complications or conversions to laparotomy. The most common predisposing factor was an adnexal mass with symptoms of pain. Torsion on the right tube is more common than on the left. Laparoscopic surgery is an effective, safe, and feasible method in the diagnosis and treatment of adnexal torsion.
\end{abstract}

I. Alkatout $(\bowtie) \cdot$ L. Mettler • W. Jonat • C. Eckmann-Scholz •

T. Schollmeyer

Department of Gynecology and Obstetrics,

University Hospitals Schleswig-Holstein,

Campus Kiel, Arnold-Heller Strasse 3, House 24,

24105, Kiel, Germany

e-mail: ibrahim.alkatout@uk-sh.de

URL: www.endo-kiel.de

M. Anlauf

Institute of Pathology, University Hospital Düsseldorf,

40225, Düsseldorf, Germany
Keywords Adnexal torsion · Laparoscopy · Pelviscopic treatment $\cdot$ Organ preservation

\section{Introduction}

Torsion of the adnexa is the fifth most common gynecologic surgical emergency [1]. The condition is more common in premenarcheal females (children or premenarcheal adolescents) in whom torsion involving previously normal adnexa may constitute up to $15-50 \%$ of adnexal torsion cases [2]. It is difficult to diagnose because although adnexal torsion may present in the form of acute pelvic pain, the symptoms can sometimes be deceptive. When the lesions are asymptomatic, the diagnosis may be made only during the surgical procedure. Doppler evaluation in cases of ovarian torsion can be a useful tool, but it was found to be normal in $60 \%$ of these cases. The absence of Doppler flow was predictive of surgically confirmed cases of ovarian torsion, demonstrating the low sensitivity but high specificity of Doppler studies in the diagnosis of torsion [3, 4].

In the past, adnexal torsion was treated by salpingooophorectomy without untwisting the adnexa to avoid potential thromboembolism from ovarian vein thrombosis [5]. However, a significant association between thromboembolism and untwisting an ischemic pedicle has never been established [6]. Recently, a review of literature concluded that the risk of pulmonary embolism after adnexal torsion was $0.2 \%$ and was not increased when the adnexa was untwisted. Over 400 cases managed with untwisting the adnexa have been reported, with no embolic phenomena $[4,6]$.

The conservative management of torsion with untwisting (detorsion) of the fallopian tube and ovary has proved to be safe and effective in multiple case series in the late 1980s and early 1990s. This type of management, first proposed by 
Way in 1946, is highly desirable since torsion occurs most often in women of reproductive age, and ovarian conservation is preferable in this age group.

Progress made in operative laparoscopy now suggests that treatment of adnexal torsion can be carried out laparoscopically which is the procedure of choice. Laparoscopic management of adnexal torsion has been shown to be feasible and preferable to laparotomy. The advantages of laparoscopy include short hospital stay and recovery time, in addition to the fact that conservative procedures, such as detorsion and ovarian cystectomy, can be done laparoscopically [7].

\section{Patients and methods}

Data from 33 patients with adnexal torsion who underwent laparoscopic management were collected retrospectively from the computerized operating logs of the Department of Obstetrics and Gynecology, University of SchleswigHolstein, Campus Kiel, Germany over an 11-year period between December 1999 and September 2010.

All patients underwent a clinical examination, ultrasound scanning, routine blood count, electrolyte analysis, urine analysis, and coagulation profile. In patients diagnosed to have an adnexal cyst, tumor markers, namely, CA125 and CEA, were measured. Other imaging techniques, such as MRI, were done in selected cases according to the sonographic findings. Presence of any predisposing factors such as adhesions, neoplasm, and pregnancy were noted.

Data regarding patient's demographics, intraoperative findings, and the operation performed were obtained from the clinical records. Cases were included in the analysis only if there was evidence of torsion of the ovary, fallopian tube, or entire adnexa at the time of definitive surgical evaluation. The final pathological diagnosis was also documented.

\section{Results}

For 33 patients, the diagnosis of adnexal torsion during the study period was confirmed. The mean age of the patients was 34.9 years (range 14-68 years). Of the 33 patients, 4 patients $(12 \%)$ were in the premenarcheal age group, 23 patients $(70 \%)$ were in the reproductive age group, and 6

Table 1 Patient demographics

\begin{tabular}{ll}
\hline Age group & No. (\%) \\
\hline Premenarcheal girls & $04(12)$ \\
Reproductive age & $23(70)$ \\
Postmenopausal & $06(18)$ \\
\hline
\end{tabular}

patients (18\%) were postmenopausal (Table 1). Four out of 23 patients in the reproductive age group $(17 \%)$ were pregnant at the time of the operative intervention. One of them had a singleton pregnancy of 10 weeks gestation and two patients had triplets [in vitro fertilization (IVF)/ICSI cycle] of 7 and 14 weeks gestation, respectively. Both of them had multiple ovarian cysts because of ovarian hyperstimulation syndrome (OHSS). One patient had cornual interstitial ectopic pregnancy of 6 weeks gestation as well as a dermoid cyst on the same side.

All 33 patients had a unilateral torsion. The torsion was more common on the right side $(61 \%, n=20)$ than on the left side (39\%,n=13). Fourteen patients (43\%) had only an ovarian torsion, 10 patients $(30 \%)$ only a tubal torsion, and 9 patients $(27 \%)$ had a torsion of the entire adnexa (Table 2 ). Multiple predisposing conditions were found in association with torsion. The most common association was adnexal cyst in 24 patients (72\%), adhesions in 10 cases $(30 \%)$, pregnancy in 4 cases $(12 \%)$, long tube in 3 cases $(9 \%)$, OHSS in 3 cases ( $9 \%$ ), endometriosis in 2 cases $(6 \%)$, and pelvic inflammatory disease (PID) in only 1 case $(3 \%)$. More than one predisposing factor exists in some patients. There was no identifiable cause in 10 cases (30\%) (Table 3 ).

The size of the adnexal mass was documented in 26 cases (79\%). Measurements were considered accurate only if the removed specimen was intact and measured at pathological examination. The diameter of the cyst ranged from 3 to $15 \mathrm{~cm}$ with a median size of $8 \mathrm{~cm}$. There were nine tumors $(35 \%)$ which measured less than $5 \mathrm{~cm}$ in size and seven tumors (27\%) which measured more than $10 \mathrm{~cm}$. The majority of them, 10 tumors (38\%), measured between 5 and $10 \mathrm{~cm}$.

The categorization of the operations ranged from a conservative procedure, such as laparoscopic detorsion, to an aggressive procedure, such as adnexectomy. There was no conversion to laparotomy. In 17 cases (52 \%), the adnexa were preserved by performing detorsion. In two cases (6\%), detorsion alone was performed, in 13 cases, (40\%) detorsion and cyst enucleation, and in another two cases $(6 \%)$, detorsion and cyst aspiration were performed (Table 4).

Following detorsion, we waited for about $30 \mathrm{~min}$, if allowed by the operation conditions, for recovery. Meanwhile, the operative field was continuously irrigated with warm saline in order to observe any sign of reperfusion. After torsion, the enlarged and blood-filled tube, ovary, or whole adnexa, with a variable diameter, are usually dark blue to

Table 2 Intraoperative data regarding side and site of torsion
Side of torsion

Site of torsion
Left, $13(39 \%)$

Ovary, $14(43 \%)$

Tube, 10 (30\%)

Adnexa, 9 (27\%)
Right, 20 (61\%) 
Table 3 Conditions associated with adnexal torsion

\begin{tabular}{ll}
\hline Condition & No. (\%) \\
\hline Ovarian cyst (functional and organic) & $24(72)$ \\
Adhesions & $10(30)$ \\
Pregnancy & $04(12)$ \\
Long tube & $03(9)$ \\
OHSS & $03(9)$ \\
Endometriosis & $02(6)$ \\
PID & $01(3)$ \\
None & $10(30)$ \\
\hline
\end{tabular}

OHSS ovarian hyperstimulation syndrome, PID pelvic inflammatory disease

black and partly necrotic. After detorsion, the according organ is left atraumatically to wait for any signs of reperfusion. This is a slight change of color towards a pinkish appearance; however, if reperfusion did not occur, the ovary, tube, or both were resected, which occurred in 16 patients (48\%). Unilateral salpingectomy was performed in 5 patients $(15 \%)$ and unilateral adnexectomy in 11 patients (33\%), 6 of them (37\%) were postmenopausal. The mean operating time was $69.2 \mathrm{~min}$ (range 40-120 min). No patient had serious complications, such as thromboembolic events, blood transfusion, febrile morbidity, or reoperation. The average duration of stay in the hospital was 2.5 days (range 1-3 days).

The histopathological reports revealed functional or developmental adnexal cyst in 15 cases $(45 \%)$, dermoid cyst in 4 cases $(12 \%)$, endometrioma in 2 cases $(6 \%)$, serous cystadenoma in 3 cases (9\%), ovarian fibroma in only 1 case (3\%), hydrosalpinx in 3 cases (9\%), and normal adnexa in 1 case (3\%) (Table 5). All removed tubes and ovaries showed focal necrosis next to hemorrhage in submucosal as well as orthotopic normal ovarian cortical tissue. There was no histopathological specimen in four patients (4\%) who underwent adnexal-sparing procedures.

\section{Discussion}

Despite recent progress with the color Doppler techniques [8], preoperative diagnosis is often difficult, and adnexal

\begin{tabular}{lll}
$\begin{array}{l}\text { Table } 4 \text { Operation per- } \\
\text { formed for adnexal } \\
\text { torsion }\end{array}$ & Operation & $\begin{array}{l}\text { No. } \\
(\%)\end{array}$ \\
\cline { 2 - 3 } & $\begin{array}{l}\text { Only detorsion } \\
\text { Detorsion and cyst } \\
\text { enucleation }\end{array}$ & $2(6)$ \\
& $\begin{array}{l}\text { Detorsion and cyst aspiration } \\
\text { Detorsion and adnexectomy }\end{array}$ & $2(6)$ \\
& $11(33)$ \\
& Detorsion and salpingectomy & $5(15)$ \\
\hline
\end{tabular}

Table 5 Pathological diagnosis

\begin{tabular}{ll}
\hline Diagnosis & No. (\%) \\
\hline Functional ovarian cyst & $7(21)$ \\
Serous cystadenoma & $3(9)$ \\
Dermoid cyst & $4(12)$ \\
Endometrioma & $2(6)$ \\
Paraovarian cyst & $7(21)$ \\
Hydrosalpinx & $3(9)$ \\
Para tubal hydatid cyst & $1(3)$ \\
Ovarian fibroma & $1(3)$ \\
Normal adnexa & $1(3)$ \\
No histological specimen & $4(12)$ \\
\hline
\end{tabular}

torsion can be confused with many other gynecological conditions. The surgical evaluation of these patients should be performed by laparoscopy, thereby avoiding unnecessary laparotomies.

Adnexal torsion is a rare condition which predominantly occurs in the reproductive age group although it has also been reported in premenarcheal girls [9, 10]. Unilateral torsion associated with an adnexal mass is seen more commonly although cases of torsion of normal adnexa have been reported [11]. The mechanism of adnexal torsion is not known conclusively; however, various theories, such as the presence of a long tube, sudden valsalva maneuver [12], pelvic congestion [13], and autonomic dysfunction of tubal peristalsis, have been suggested [14]. Factors that could possibly influence the occurrence of fallopian tube torsion are divided into two types: internal and external (Table 5). Taken together, the existing reports indicate that the mechanism underlying tubal torsion is apparently a sequential mechanical event (Table 6).

In our study, the most common predisposing factor was adnexal cyst in 24 patients $(72 \%)$. Ten patients $(30 \%)$ had no individual predisposing factors; however, an equal number of patients (30\%) had adhesions which may promote torsion. These results correspond with current literature [15]. Four patients (12\%) were pregnant. The presence of

Table 6 Intrinsic and extrinsic causes of fallopian tube torsion

\begin{tabular}{ll}
\hline Intrinsic & Extrinsic \\
\hline Congenital anomalies & $\begin{array}{c}\text { Changes in the neighboring } \\
\text { organs }\end{array}$ \\
$\begin{array}{l}\text { Excessive length of tube or spiral } \\
\text { course }\end{array}$ & $\begin{array}{l}\text { Neoplasm, adhesions, } \\
\text { pregnancy }\end{array}$ \\
$\begin{array}{l}\text { Acquired pathology } \\
\text { Hydrosalpinx, hematosalpinx, } \\
\text { neoplasm, surgery }\end{array}$ & $\begin{array}{c}\text { Movement or trauma to the } \\
\text { pelvic organs }\end{array}$ \\
$\begin{array}{l}\text { Autonomic dysfunction and } \\
\text { abnormal peristalsis }\end{array}$ & Pelvic congestion \\
\hline
\end{tabular}


Table 7 Possible mechanisms for tubal torsion
- Mechanical disturbance

- Venous obstruction

- Lymphatic congestion

- Diffuse edema

- Tubal enlargement

- Tubal torsion

long tube, OHSS, endometriosis, and PID were all associated with less than $10 \%$ of cases.

Adnexal torsion was more common on the right side $(61 \%)$ than on the left $(39 \%)$ which may be attributed to the protective effect of the sigmoid colon on the left side and subclinical appendicial infection on the right side, as confirmed, e.g., by Nichols [14]. In the present study, we encountered isolated ovarian torsion in 14 (43\%), entire adnexal torsion in $9(27 \%)$, and isolated fallopian tube torsion in 10 (30\%) patients. However, isolated fallopian tube torsion has been reported as sporadic cases by many authors $[9,16,17]$.

The most common pathological diagnosis in our series was benign ovarian neoplasm $(24 \%)$. Half of them were dermoid cyst, functional ovarian cyst $(21 \%)$, paraovarian and paratubal cyst (24\%), endometrioma (6\%), hydrosalpinx (9\%), and normal adnexa (3\%). There was no case of malignancy in our series. Many studies report organic ovarian pathologies to be the most common pathological finding $[1,4]$. Intrinsic and extrinsic causes of fallopian tube torsion and the possible mechanisms for tubal torsion are given in Tables 5 and 7.

Historically, the treatment of choice for adnexal torsion has been laparotomy and unilateral salpingo-oophorectomy. Although, there has been concern about the significant risk of thromboembolic events by detorsion, various reports, starting from as early as 1946 by S. Way, have suggested the safety of ovarian conservation by detorsion. Laparoscopy has been shown to be a favorable option in patients with torsion. There has been a trend towards increased used of laparoscopy and adnexal-sparing procedures in many centers because of its obvious benefits regarding safety, reliability, and preserving fertility $[1,7,18,19]$.

For the whole of our series, we were able to use laparoscopic surgery to treat $100 \%$ of cases (33 patients) because there was no suspicion of neoplastic pathology during the diagnostic part of the laparoscopy. Seventeen cases of adnexal torsion ( $52 \%$ of patients) benefited from conservative laparoscopic treatment. These patients underwent detorsion only, with or without cyst aspiration or enucleation. The majority of these were young women desiring fertility. In $48 \%$ of cases, detorsion followed by salpingectomy or adnexectomy was performed. More than half of the patients having an adnexectomy were postmenopausal. In the recent literature, the rate of conservative laparoscopic treatment varies from 35 to $93 \%[1,4,7,18,20]$.

Laparoscopy in early pregnancy provides a better chance for successful continuation of pregnancy. In our study, there were four pregnant women at the time of conservative laparoscopic surgery. One of the pregnant women who underwent laparoscopic detorsion and cyst aspiration during the 10th week of gestation has an ongoing pregnancy of 30 weeks gestation. Two women of 7 and 14 weeks gestation, with triplets after IVF, miscarried at 20 and 22 weeks, respectively, due to cervical incompetence. The last one had an interstitial ectopic pregnancy. Laparoscopy in pregnancy, especially in later pregnancy, is technically difficult owing to the increased risk of perforation and bleeding. Postoperatively, there is an increased risk of miscarriage or preterm delivery [21].

\section{Conclusion}

This study confirms that laparoscopy is the preferable approach for diagnosis and treatment of adnexal torsion. Conservative treatment should be considered in women within the reproductive age, still desiring fertility. Adnexectomy should only be considered beyond the reproductive age and really only in cases with extreme pathology on the adnexa.

Conflict of interest The authors report no conflicts of interest. The authors alone are responsible for the content and writing of the paper.

\section{References}

1. Balci O, Icen MS, Mahmoud AS, Capar M, Colakoglu MC (2010) Management and outcomes of adnexal torsion: a 5-year experience. Arch Gynecol Obstet 284(3):643-646. doi:10.1007/s00404$010-1702-z$

2. Pansky M, Abargil A, Dreazen E, Golan A, Bukovsky I, Herman A (2000) Conservative management of adnexal torsion in premenarchal girls. J Am Assoc Gynecol Laparosc 7(1):121-124

3. Pena JE, Ufberg D, Cooney N, Denis AL (2000) Usefulness of Doppler sonography in the diagnosis of ovarian torsion. Fertil Steril 73(5):1047-1050

4. Erdemoglu M, Kuyumcuoglu U, Guzel AI (2011) Clinical experience of adnexal torsion: evaluation of 143 cases. J Exp Ther Oncol 9(3):171-174

5. Zweizig S, Perron J, Grubb D, Mishell DR Jr (1993) Conservative management of adnexal torsion. Am J Obstet Gynecol 168(6 Pt 1):1791-1795

6. McGovern PG, Noah R, Koenigsberg R, Little AB (1999) Adnexal torsion and pulmonary embolism: case report and review of the literature. Obstet Gynecol Surv 54(9):601-608

7. Oelsner G, Cohen SB, Soriano D, Admon D, Mashiach S, Carp H (2003) Minimal surgery for the twisted ischaemic adnexa can preserve ovarian function. Hum Reprod 18(12):2599-2602

8. Fleischer AC, Brader KR (2001) Sonographic depiction of ovarian vascularity and flow: current improvements and future applications. J Ultrasound Med 20(3):241-250

9. Schollmeyer T, Soyinka AS, Mabrouk M, Jonat W, Mettler L, Meinhold-Heerlein I (2008) Chronic isolated torsion of the left fallopian tube: a diagnostic dilemma. Arch Gynecol Obstet 277 (1):87-90. doi:10.1007/s00404-007-0411-8 
10. Breech LL, Hillard PJ (2005) Adnexal torsion in pediatric and adolescent girls. Curr Opin Obstet Gynecol 17(5):483-489. doi:00001703-200510000-00008

11. Bider D, Mashiach S, Dulitzky M, Kokia E, Lipitz S, Ben-Rafael Z (1991) Clinical, surgical and pathologic findings of adnexal torsion in pregnant and nonpregnant women. Surg Gynecol Obstet 173 (5):363-366

12. Rosado WM Jr, Trambert MA, Gosink BB, Pretorius DH (1992) Adnexal torsion: diagnosis by using Doppler sonography. AJR Am J Roentgenol 159(6):1251-1253

13. Stock RJ (1987) Clinicopathologic changes resulting from adnexal torsion. J Reprod Med 32(3):201-207

14. Nichols DH, Julian PJ (1985) Torsion of the adnexa. Clin Obstet Gynecol 28(2):375-380

15. Argenta PA, Yeagley TJ, Ott G, Sondheimer SJ (2000) Torsion of the uterine adnexa. Pathologic correlations and current management trends. J Reprod Med 45(10):831-836
16. Kurzbart E, Mares AJ, Cohen Z, Mordehai J, Finaly R (1994) Isolated torsion of the fallopian tube in premenarcheal girls. J Pediatr Surg 29(10):1384-1385

17. Wong SW, Suen SH, Lao T, Chung KH (2010) Isolated fallopian tube torsion: a series of six cases. Acta Obstet Gynecol Scand 89(10):1354-1356. doi:10.3109/00016349.2010.503870

18. Oelsner G, Bider D, Goldenberg M, Admon D, Mashiach S (1993) Long-term follow-up of the twisted ischemic adnexa managed by detorsion. Fertil Steril 60(6):976-979

19. Way S (1946) Ovarian cystectomy of twisted cysts. Lancet 2 (6411):47

20. Mage G, Canis M, Manhes H, Pouly JL, Bruhat MA (1989) Laparoscopic management of adnexal torsion. A review of 35 cases. J Reprod Med 34(8):520-524

21. Koo YJ, Lee JE, Lim KT, Shim JU, Mok JE, Kim TJ (2011) A 10year experience of laparoscopic surgery for adnexal masses during pregnancy. Int J Gynaecol Obstet 113(1):36-39 